\title{
Thyroid Function in Bulimia Nervosa
}

\author{
Adela R. Spalter, Harry E. Gwirtsman, Mark A. Demitrack, and Philip W. Gold
}

\begin{abstract}
Bulimia nervosa is characterized by episodes of binge eating. Bulimic patients have diminished caloric requirements and reduced metabolic rate. Because thyroid function is an important modulator of metabolic rate, we sought to clarify conflicting reports concerning this parameter in bulimic patients. Thyroid indices were examined in 18 bulimics at admission and after 3 weeks of abstinence. Patients had thyroid indices in the normal range at admission but slightly diminished triiodothyronine $\left(T_{3}\right)$ compared with control subjects $(\mathrm{n}=28)$. Significant declines in $T_{3}$ and thyroxine and increases in thyrotropin were noted after 3 weeks of abstinence. At abstinence, $T_{3}$ was positively correlated with caloric intake, protein, fat, and carbohydrate consumption and inversely correlated with percent ideal body weight. We hypothesize that binge-purge behavior may transicntly increase thyroid indices and, consequenity, metabolic rate in patients with bulimia nervosa. Furthermore, decreases in $T_{3}$ following abstinence may be related to diminished caloric consumption or may reflect hypothalamic-pituitary dysregulation in these patients.
\end{abstract}

Key Words: Bulimia, metabolism. thyroxine, triiadothyronine, thyrotropin, caloric intake, hypothalamic-pituitary axis

\section{Introduction}

Bulimia nervosa is an eating disorder characterized by a pattern of uncontrolled, rapid ingestion of large amounts of food, often followed by self-induced vomiting or other purging behavior. Several studies have examined both thyroid function and resting metabolic rate (RMR) in bulimic patients. Obarzanek et al (1991) reported that bulimics with 3 weeks of abstinence had significantly lower plasma triiodothyronine $\left(T_{3}\right)$ values as well as a significantly lower RMR compared with control subjects. Devlin et al (1990) found low RMR and normal thyroid function in bulimic outpatients and inpatients, but the degree of abstinence

From the Clinical Neuroendocrinology Branch (ARS. HEG. PWG), National In stitute of Mental Health. Bethesda, Maryland; and University of Michigan Medical Center (MAD), Ann Arbor, Michigan.

Address reprint requests to Harry E. Gwirtsman. M.D. , National Institute of Mental Health. Mood. Anxiety, and Personality Disorders Branch. 5600 Fisher Lane. Room 10C-24, Rockville, MD 20857.

Roceived Juliy it, is90; revised Octüber 30, 1992. was not specified. Pirke et al (1985b) described low $T_{3}$ in bulimic patients whereas Devlin et al (1990) found normal $T_{3}$. Abnormalities in thyroid function in anorexia nervosa and in starved patients have been described frequently. Underweight anorectic patients have shown low levels of $T_{3}$ that increase longitudinally with increasing weight (Pirke et al 1985a). Vagenakis et al (1975), in a study of experimentally induced starvation, found a significant reciprocal correlation between $T_{3}$ and reverse $T_{3}\left(\mathrm{r}_{3}\right)$ during starvation, which was explained as secondary to a decreased conversion of peripheral thyroxine $\left(T_{4}\right)$ to $T_{3}$.

Studies that have examined the thyrotropin (TSH) response to thyrotropin-releasing hormone (TRH) in bulimic patients have also produced conflicting dat?. Whereas some observers reported a delayed peak and a blunted response of TSH (Levy et al 1988; Kiyohara et al 1987; Gwirtsman et al 1983), suggesting a hypothalamic-pituitary abnormality, others reported normal TSH response to TRH (Norris et al 1985). 
No investigation to date has explored the changes in thyroid function in bulimic patients during states of bingepurge behavior and after abstinence. To examine this issue. we studied thyroid function in normal-weight bulimic women hoth at admission and after 3 weeks of abstinence.

\section{Method}

\section{Patients}

Eighteen normal-weight women who met DSM-III-R criteria for bulimia nervosa were admitted to the Eating Disorder Unit of the National Institute of Mental Health (NIMH). Control subjects were 28 normal female volunteers recruited at the NIMH.

All 18 bulimic patients had well-characterized eating patterns of bulimia, with a mean duration of illness of 5.1 years (range 1-11) and a mean of 22.1 hinges ner week (range 5-70). Patients were free of medicationi for at least 4 weeks before their admission.

Patients participated in a behaviorally oriented treatment program that included a 6-8-week period of ahstinence from binging and purging. Patients were observed frequently, including bathroom visits, to prevent surreptitious binging and purging. They received psychological and nutritional counseling and were encouraged to maintain a stable baseline weight (within $\pm 1 \mathrm{~kg}$ ).

\section{Procedures}

The following laboratory tests were performed in the bulimic patients at admission and after 3 weeks of abstinence. All laboratory tests were performed in the Chemistry Laboratory of the National Institutes of Health.

$\mathrm{T}_{3}$ serum levels were measured using a Quanticoat $T_{3}$ radioimmunoassay (Kallestad Laboratory, Inc.; Craska, Minniesutá) (Eastman et al 1975). This procedure measures $\mathrm{T}_{3}$ concentrations between 0 and $800 \mathrm{ng} / \mathrm{dl}$, with a sensitivity of $15 \mathrm{ng} / \mathrm{dl}$ and a coefficient of variation (CV) of $3.9 \%$. Normal values range from 88 to $162 \mathrm{ng} / \mathrm{dl}$. $\mathrm{T}_{4}$ was determined by TDx $\mathrm{T}_{4}$ PLUS (Abbott Laboratory; Abbott Park, lllinois) (Symons and Vining 1985) assay, which utilizes fluorescence polarization immunoassay technology. Sensitivity was $1.0 \mu \mathrm{g} / \mathrm{dl}$, with a CV of $3.8 \%$; normal range was between 5 and $10 \mu \mathrm{g} / \mathrm{dl}$. TSH was measured by an immunoradiometric assay magnetic solid-phase method (Serono Diagnostics; Coinsins, Switzerland) (Rattle et al 1984). Sensitivity was between 0.02 and $0.04 \mathrm{mlU} / \mathrm{ml}$, with a CV of $5.0 \%$; normal range was $0.5-4.6 \mathrm{mlU} / \mathrm{ml}$. Thyroid-binding globulin (TBG) was measured by radioimmunoassay (Corning's IMMO PHASE; Medfield, Massachusetts) (Gershengorn et al 1976). The detection range is between 10 and $60 \mathrm{mg} / \mathrm{ml}$ with a CV of $4.5 \%$; normal values are $12-28 \mathrm{mg} / \mathrm{ml}$.
Caloric intake was calculated for 7 duys preceding the thyroid function assessment during abstinence by using a food-exchange list; food composition tables; and Atwater's nutrient conversion factors of 4,9 , and $4 \mathrm{kcal} / \mathrm{g}$ for carbohydrates, fat, and protein, respectively (Petersen et al 1986). All foods leaving the kitchen were measured and recorded. The amount of food remaining on the tray was also recorded and subiracted from the original amount.

\section{Statistical Analysis}

Statistical analysis was carried out using mean values \pm SD. Bulimic patients were compared with control subjects by using nonpaired two-tailed Student's $t$-tests. Admission versus abstinence values in bulimic patients were compared using paired two-tailed $t$-tests. Correlations were calculated using Pearson's correlation coefficient. All $p$ values were two-tailed.

\section{Results}

There were no significant differences in age, height, weight, and percent ideal body weight (\% IBW) between bulimic patients and control subjects (Table 1). At admission, bulimic patients had significantly lower $\mathrm{T}_{3}(t=2.79 ; \mathrm{df}=$ $44 ; p=0.03$ ) and a trend toward lower TSH values $(t=1.79 ; \mathrm{df}=43 ; p=0.08)$ compared with normal control subjects. No significant differences were found in $\mathrm{T}_{4}$ and TBG values. There was no significant correlation between $\mathrm{T}_{3}$ at admission and \% IBW $[r=0.28$; $\mathrm{df}=16$; $p=$ not significant (NS)]. Because bulimic patients showed a trend to lower \%IBW, we introduced the \%IBW as a covariate into the analysis. The analysis of covariance still indicated a trend for bulimic patients to have lower $T_{3}$ than control subjects $(p=0.07)$.

After 3 weeks of austincha, Lunininic patients showed a significant decrease in $\mathrm{T}_{3}(t=3.9 ; \mathrm{df}=17 ; p=0.001)$, a significant decrease in $\mathrm{T}_{4}(t=2.3$; $\mathrm{df}=9 ; p=0.05)$, and a significan: increase in TSH values $(t=3.6$; $\mathrm{df}=$ $17 ; p=0.002$ ) (Table 2 ). There were no significant changes in TBG values.

There also were significant correlations between $T_{3}$ at abstinence and caloric intake $(r=0.78$; $\mathrm{df}=16 ; p=$ $0.001)$ and protein $(r=0.65: \mathrm{df}=16 ; p=0.003)$, Fat $(r=0.73 ; \mathrm{df}=16 ; p=0.0005)$, and carbohydrate consumption $(r=0.55 ; \mathrm{df}=16 ; p=0.01$ ).

Because all of our bulimic patients demonstrated vomiting behavior associated with binging, we examined whether there was any influence of dehydration on $T_{3}$ indices at admission. We found no significant correlations between admission $T_{3}$ levels and admission sodium, potassium. osmolarity, hematocrit, and chloride levels nor with body weight. 
Table 1. Demographic Characteristics of 18 Bulimic Patients and 28 Control Subjects ${ }^{a}$

\begin{tabular}{lccc} 
& $\begin{array}{c}\text { Bulimic patients } \\
(n=18)\end{array}$ & $\begin{array}{c}\text { Control subjects } \\
(n=28)\end{array}$ & $p$ Value \\
\hline Age (yr) & $21.7 \pm 2.7$ & $24.1 \pm 3.9$ & NS \\
Weight $(\mathrm{kg})$ & $56.5 \pm 5.4$ & $58.2 \pm 5.4$ & NS \\
Height $(\mathrm{cm})$ & $164.5 \pm 12.9$ & $163.7 \pm 4.7$ & NS \\
\%IBW & $93.0 \pm 6.4$ & $97.0 \pm 7.4$ & NS \\
Duration $(\mathrm{yr})$ & $5.1 \pm 3.0$ & - & \\
Binges/wk & $22.1 \pm 17.1$ & - & \\
\hline
\end{tabular}

${ }^{a}$ NS, not significant; \%lBW, percent ideal body weight; values are mean \pm SD.

There was no significant correlation between $T_{3}$ and \%IBW at abstinence ( $r=-0.03$; $\mathrm{df}=16 ; p=\mathrm{NS}$ ). Finally, there were no significant differences between \%IBW at admission and abstinence (mean \pm SD: admission, $93.0 \pm 6.4$; abstinence, $92.3 \pm 4.7$; paired $t$-tests 1.8 ; $\mathrm{df}=16 ; p=\mathrm{NS}$ ).

No significant correlation was found between thyroid function and other clinical variables, such as age, binges per week, laxative abuse, and duration of illness. There was a significant inverse correlation between \% IBW and $\Delta T_{3}$ (admission $T_{3}-T_{3}$ after 3 weeks of abstinence); patients with a higher \%IBW showed a smaller decrease in $\mathrm{T}_{3}$ after abstinence ( $r=0.5$; df $=16 ; p=0.02$ ).

Although the bulimic patients as a group showed a significant decline in $T_{3}$ values after 3 weeks of abstinence, examination of the raw data showed important decrements in $T_{3}$ in some patients but not in others. Thus, to examine factors associated with $T_{3}$ decline after abstinence, we performed a median split of our bulimic patient sample based on $\Delta T_{3}$. The mean $\Delta T_{3}$ (admission $T_{3}-T_{3}$ after 3 weeks of abstinence) in the low-change group was $3.8 \pm 12.4$, whereas in the high-change group it was 55.2 \pm 23.2. The most important finding was that $T_{3}$ at admission was significantly lower in the low-change group compared with the high-change group $(90.1 \pm 17.9$ versus $115.8 \pm 19.4 \mathrm{ng} / \mathrm{dl} ; t=-5.8 ; \mathrm{df}=16 ; p=0.001$ ). Similar results were found in $\mathrm{T}_{4}$ at admission $(6.0 \pm 0.9$ versus $8.2 \pm 1.7 \mu \mathrm{g} / \mathrm{dl} ; t=-3.4 ; \mathrm{df}=16 ; p=0.03$ ) and TBG at admission $(21.0 \pm 1.8$ versus $24.3 \pm 3.9$ $\mathrm{ng} / \mathrm{dl} ; t=-2.3$; df $=16 ; p=0.03$ ). On the other hand, there were no significant differences in TSH between groups. The $\Delta \mathrm{T}_{3}$ in the low-change group was so low as to have possibly produced a "floor effect" (there would be no significant decline in $T_{3}$ ). To attempt to clarify this, we correlated admission $T_{3}$ with decline in $T_{3}$ and found significant relationships between these parameters in the entire group of patients $(r=0.667 ; n=18 ; p=0.01)$ and a trend in the high-change group $(r=0.556 ; n=5 ; p=$ 0.09 ) but not in the low-change group $(r=0.109 ; n=$ $5 ; p=N S$ ). We also compared a subset of patients in the low- and high-change groups matched for the admission $\mathrm{T}_{3}$ values. To match the low- and high-change groups for the initial $T_{3}$ values, we included only pairs with the same $T_{3}$ values at admission. This tight matching procedure produced five pairs. In each group (low and high change), the $T_{3}$ values were similar (low change $102.3 \pm 12.5$ versus high change $103.2 \pm 12.5$ ). The high-change group still showed a significantly greater decline in $T_{3}$ values after 3 weeks of abstinence compared with the low-change group (99.6 \pm 16.5 vs $58.2 \pm 10 ; t=4.8$; df $=8 ; p$ $=0.001$ ). Although the above correlational analysis indicates that a floor effect may be partially responsible for differences in $\Delta T_{3}$ between the low- and high-change groups, the analysis of the five pairs of low- and high-change-

Table 2. Thyroid Function in Bulimic Patients and Control Subjects ${ }^{a}$

\begin{tabular}{lccc}
\hline & \multicolumn{2}{c}{ Bulimic Patients $(n=18)$} & $\begin{array}{c}\text { Control } \\
\text { subjects } \\
(n=28)\end{array}$ \\
\cline { 2 - 4 } & \multicolumn{1}{c}{ Admission } & Abstinence & $115.4 \pm 16.4$ \\
$\mathrm{~T}_{3}(\mathrm{ng} / \mathrm{dl})^{b}$ & $102.9 \pm 22.4$ & $73.5 \pm 23.8$ & $7.1 \pm 1.3$ \\
$\mathrm{~T}_{4}(\mu \mathrm{g} / \mathrm{dl})^{c}$ & $7.1 \pm 1.7$ & $5.5 \pm 0.9$ & $2.5 \pm 1.2$ \\
$\mathrm{TSH}(\mu \mathrm{U} / \mathrm{ml})^{d}$ & $2.0 \pm 1.0$ & $2.7 \pm 1.0$ & $21.2 \pm 2.6$ \\
$\mathrm{TBG}(\mathrm{mg} / \mathrm{ml})$ & $22.5 \pm 3.4$ & $23.0 \pm 3.4$ & \\
\hline
\end{tabular}

${ }^{a} T_{3}$, triiodothyronine; $T_{4}$, thyroxine; $T S H$, thyrotropin; TBG, thyroxine-binding globulin; values are mean $\pm S D$.

bulimic patients: admission vs. controls, $p=0.03$; admission vs. abstinence, $p=0.001$.

'Bulimic patients, admission vs. abstinence, $p<0.05$.

${ }^{d}$ Bulimic patients, admission vs. abstinence, $p=0.002$. 
group patients, matched for equivalence of admission $\mathbf{T}_{3}$, is evidence that the floor-effect hypothesis cannot fully explain the differences in $\Delta T_{3}$ between these two groups.

Other findings were that the low-change group had consumed significantly larger amounts of calories during the week before the abstinence assessment compared with the high-change group (1596.2 \pm 233.1 versus $1296 \pm 203.3$; $t=2.9 ; \mathrm{df}=16 ; p=0.01)$. Similar results were found in consumption of proteins $(75 \pm 16.8$ versus $59.9 \pm$ $11.6 \mathrm{~g} ; t=2.2 ; \mathrm{df}=16 ; p=0.04)$ and fat $(47.5 \pm$ 9.2 versus $35.7 \pm 8.7 \mathrm{~g} ; t=2.8 ; \mathrm{df}=16 ; p=0.01$ ). No significant differences were found in carbohydrate consumption.

\section{Discussion}

The major findings of this study are the following: First, there was a significant decline in $T_{3}$ and $T_{4}$ and an increase in TSH values in normal-weight bulimic patients after 3 weeks of abstinence from binge-purge behavior. Second, we found a significant correlation between $T_{4}$ and consumption of calories, protein, fat, and carbohydrates during the abstinence period. Bulimic patients at admission had $T_{3}$ values in the normal range, but these were significantly lower than $\mathbf{T}_{3}$ values in age-matched normal women. Even after controlling for $\% \mathrm{IBW}$, differences in $\mathrm{T}_{3}$ (admission versus abstinence) still remained significant. TSH values tended to be slightly lower $(p=0.07)$ in the bulimic patients, but when \%IBW was introduced into the analysis as a covariate, this trend became entirely nonsignificant.

In the present study, we found a significant decrease in both $\mathrm{T}_{3}$ and $\mathrm{T}_{4}$, as well as a significant increase in TSH after 3 weeks of abstinence; however, we strongly doubt that these changes in thyroid indices were related solely to thyroid gland dysfunction. If this were the case, the pituitary response and consequent TSH increase would have been considerably greater, raising TSH values outside the normal range. This can be seen, for example, in thyroid gland dysfunction due to lithium carbonate, where TSH values are increased long before $T_{4}$ and $T_{3}$ levels show any decline whatsoever. Because this degree of TSH increase did not occur, we would postulate that the feedback of the thyroid gland on the hypothalamus or the pituitary gland may be somewhat impaired in this patient population.

"Set-point" theory indicates that the body attempts to "defend" an apparently preprogrammed weight level and that this phenomenon is relatively independent of esthetic food preferences. The decline in $T_{3}$ and perhaps $T_{4}$ between admission and abstinence may be explained by the low-calorie diet that bulimic patients were consuming to defend a weight set point that was artificially low for them. Therefore, bulimic patieiits would be expected to reset their metabolic rate downward to compensate for the lowered calorie intake. In support of this contenticis, several observers demonstrated that level of activity of the thyroid

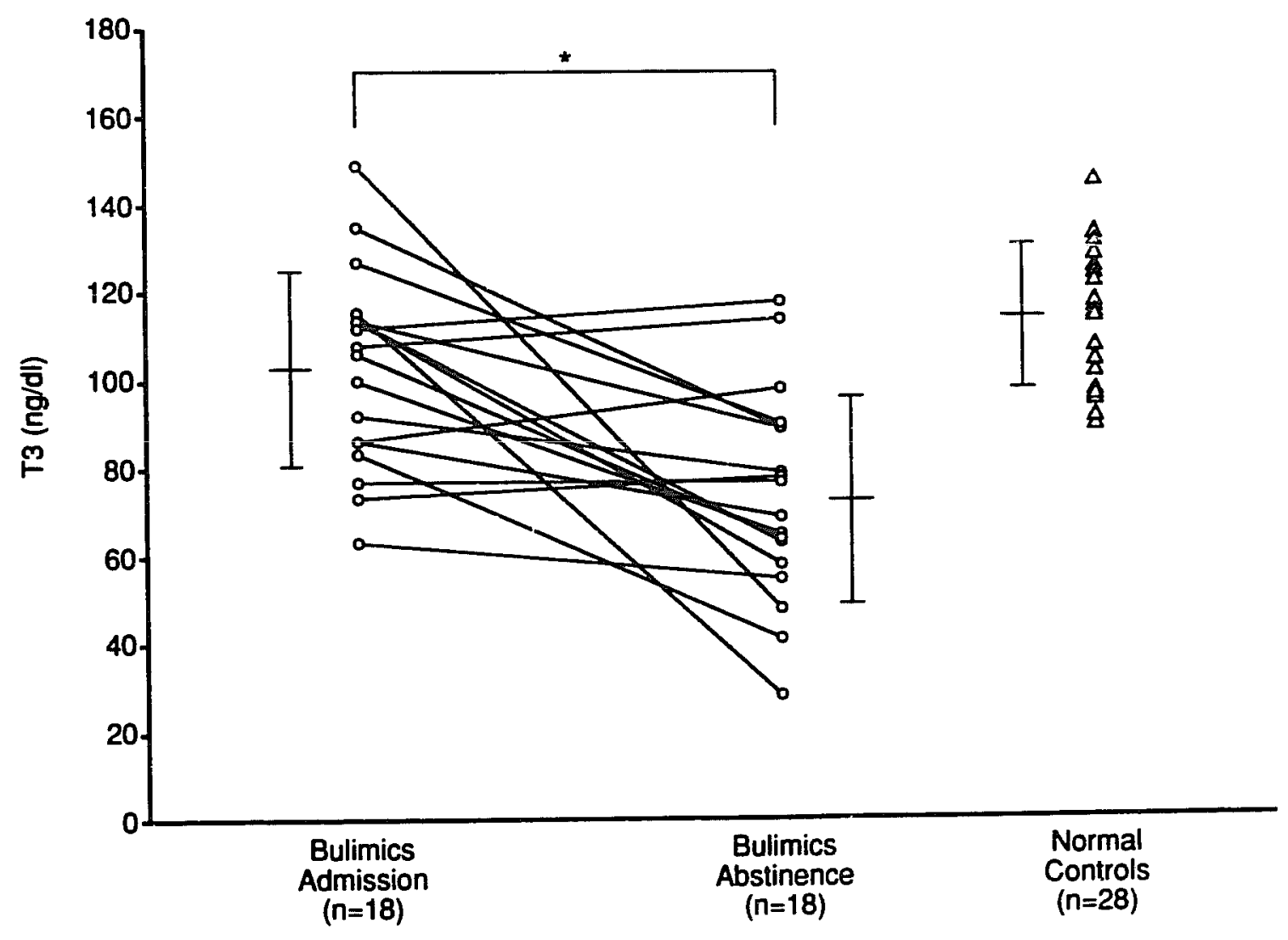

Figure $1 T_{3}$ changes at admission and after 3 weeks of abstinence in bulimic patients compared with normal control subjects; ${ }^{*} p=0.001$. 
axis significantly influences the metabolic rate (Danforth 1983; Acheson et al 1984; Grant et al 1978; Serog et al 1982; Katzeff et al 1986; Banows and Snook 1987). Obarzanek et al (1991) found that bulimic patients had significantly lower $T_{3}$ and RMR values after 3 weeks of abstinence compared with control subjects, and they also found a significant correlation between mean caloric intake during the weight-stable period and RMR in their sample. Although Devlin et al (1990) found normal thyroid function and low RMR in bulimics, the degree of abstinence was not specified; however, in agreement with our results, Altemus et al (1991) recently reported that both metabolic rate and thyroid function decreased in a group of hospitalized bulimic patients. Although they were unable to correlate these changes in thyroid indices and metabolic rate, this was due to the small number of subjects and the degree of variance in the metabolic measurements.

Low-calorie intake and dietary composition are known to modify $\mathrm{T}_{3}$ and $\mathrm{rT}_{3}$ plasma values (Spaulding et al 1976; Danforth et al 1975; Jung et al 1980; Koppeschaar et al 1985). Spaulding et al (1976) demonstrated that both fasting and complete absence of dietary carbohydrate were significantly associated with a decline in $T_{3}$, but only complete fasting showed an increase in $\mathrm{rT}_{3}$ in a group of six euthyroid obese subjects. No ciianges in either $T_{3}$ or $\mathrm{rT}_{3}$ were found when the diet contained at least $50 \mathrm{~g}(25 \%)$ of carbohydrates, and no changes were found in $\mathrm{T}_{4}$ under any of the experimental conditions. Our patients, however, showed a significant decrease in $\mathrm{T}_{3}$ despite having a normal amount of carbohydrates in their diets, although decreased carbohydrate consumption was correlated with a larger decrease in $T_{3}$. Methodological differences between our study and that of Spaulding et al (1976) are that our group of bulimic patients were normal-weight women, their diet was $1446 \mathrm{kcal} / \mathrm{day}$ (mean), and they maintained their weight, whereas Spaulding et al did not specify whether there was any weight change in their patients during the study. Although we did not systematically collect caloric data in our control group, we demonstrated in a previous sample of bulimic patients and control subjects, under identical conditions, that control subjects tend to have higher caloric intake compared with bulimic patients (Gwirtsman et al 1989). This finding has recently been replicated by Weltzin et al (1991).

One possible explanation for the difference in thyroid function found in bulimic patients at admission compared with abstinence is the potential stress of acute inpatient psvchiatnc hospitalization. Previous studies (Chopra et al 1990; Morley and Shafer 1982; Cohen and Swigar 1979) have demonstrated that patients admitted to acute psychiatric units have elevations in $\mathbf{T}_{3}, \mathbf{T}_{4}$, and TSH and that these indices will normalize within 7-21 days of admission. One important difference in our population is that TSH actually showed an increase with abstinence; however, because of this concern, we compared thyroid indices in our bulimic inpatients with another group of bulimic

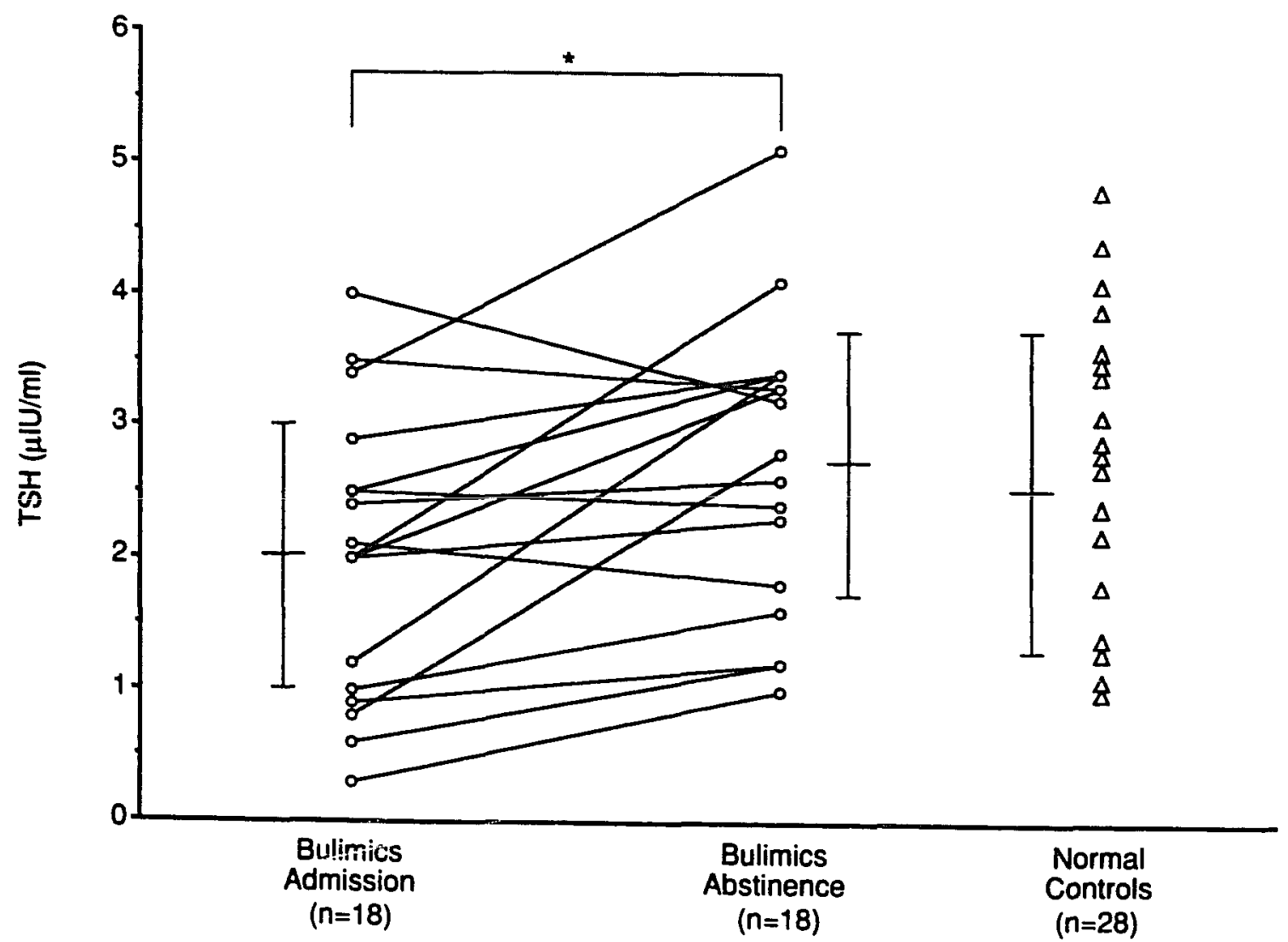

Figure 2 TSH changes at admission and after 3 weeks of abstinence in bulimic patients compared with normal control subjects; ${ }^{*} p=0.002$. 
outpatients to ascertain whether the stress of hospitalization alone was sufficient to increase these parameters in bulimic patients. We found that the group of bulimic outpatients $(n=12)$ had $\mathrm{T}_{3}(115.9 \pm 12.6), \mathrm{T}_{4}(7.0 \pm 1.6)$, and TSH (1.7 \pm 1.6$)$ levels that were not significantly higher than those in our bulimic inpatients. This argues against the hypothesis that the stress of inpatient hospitalization was solely responsible for the difference in thyroid function seen between the acute and abstinent states.

Decreased thyroid hormone levels in bulimic patients may reflect a variant of the sick euthyroid syndrome, where $\mathbf{T}_{4}$ is normal, $\mathbf{T}_{3}$ is low, and TSH is normal. Subclinical hypothyroidism secondary to thyroid gland dysfunction seems unlikely given the arguments enumerated above and also considering that normal and blunted TSH responses to TRH stimulation have been reported in bulimic patients (Norris et al 1985; Kaplan et al 1989). We cannot exclude

\section{References}

Acheson E, Jequier E, Burger A, Danforth E Jr (1984): Thyroid hormones and thermogenesis: the metabolic cost of food and exercise. Metabolism 33:262.

Altemus M, Hetherington MM, Flood M, et al (1991): Decrease in resting metabolic rate during abstinence from bulimic behavior. Am J Psychiatry 148:1071.

Barrows K, Snook JT (1987): Effects of a high-protein, verylow-calorie diet on resting metabolism, thyroid hormones, and energy expenditure of obese middle-aged women. Am J Clin Nutr 45:391.

Chopra IJ, Solomon DH, Shang Huan T (1990): Serum thyrotropin in hospitalized psychiatric patients: evidence for hyperthyrotropinemia as measured by an ultra sensitive thyrotropin assay. Metabolism 39:538.

Cohen KL, Swigar ME (1979): Thyroid function screening in psychiatric patients. JAMA 242:254.

Danforth E Jr (1983): The role of thyroid hormones and insulin in the regulation of energy metabolism. Am J Clin Nutr 38:1006.

Danforth E, Sims AH, Horton ES, Goldman RF (1975): Correlation of serum triiodothyronine concentrations $\left(T_{3}\right)$ with dietary composition, gain in weight and thermogenesis in man (abstract 54). Diabetes 24:406.

Devlin MJ, Walsh TB, Kral JG, Heymsfield SB, Pi-Sunyer FX, Dantzic S (1990): Metabolic abnormalities in bulimia nervosa. Arch Gen Psychiatry 47:144.

Eastman CJ, Corcoran JM, Ekins RP, Williams ES, Navarro JDN (1975): The radioimmunoassay of triiodothyronine and its clinical applications. $J$ Clin Pathol 28:225.

Gershengorn MC, Larsen PR, Robbins J (1976): Radioimmunoassay for serum thyroxine-binding globulin: results in normal subjects and in patients with hepatocellular carcinoma. $J$ Clin Endocrinol Metab 42:907.

Grant AM, Edwards DM, Howard AN, Challand GS, Wraight EP, Mills IH (1978): Thyroida! hormone metabolism in obesity during semi-starvation. Clin Endocrinol (Oxf) 9:227.

Gwirtsman HE, Roy-Byrne P, Yager J, Gemer RH (1983): Neuroendocrine abnormalities in bulimia. Am J Psychiatry 140:559. the possibility that bulimic patients are chemically hypothyroid in an abstinent state owing to a deficiency of the hypothalamic TRH neuron. During binge-purge activity, there may be activation of the hypothalamic-pituitarythyroid axis, causing an apparent normalization of the thyroid indices. Although the consequences of the relative increase in thyroid function are unknown, this change could conceivably increase the metabolic rate. Alternatively, the decline in $\mathbf{T}_{4}$ from admission to abstinence that we reported in the bulimic patients may be due to increased peripheral conversion of $T_{4}$ to reverse $T_{3}$. Because we did not measure $\mathrm{rT}_{3}$, we could not examine this hypothesis directly.

To further explore these issues, future studies should examine patients longitudinally with TRH stimulation tests and $\mathrm{rT}_{3}$ and with concurrent indices in metabolic rate both while binging and purging and during abstinence.

Gwirtsman HE, Kaye WH, Obarzanek E, George DT, Jimerson DC, Ebert MH (1989): Decreased caloric intake in normal weight patients with bulimia. Am J Clin Nutr 49:86.

Jung RT, Shetty PS, James WPT (1980): The effect of refeeding after semi-staruation on catecholamine and thyroid metabolism. Int J Obes 4:95.

Kaplan AS, Garfinkel PE, Brown GM (1989): The DST and TRH test in bulimia nervosa. Br J Psychiatry 154:86.

Katzeff HL, O’Connell M, Horton ES, Danforth E Jr, Young JB, Landsberg L (1986): Metabolic studies in human obesity during overnutrition and undernutrition: thermogenic and hormonal response to norepinephrine. Metabolism 35:166.

Kiyohara K, Tamai H, Karibe C, et al (1987): Serum TSH responses to TRH in patients with anorexia nervosa and bulimia: influence of changes in body weight and eating disorders. Psychoneuroendocrinology 12:21.

Koppeschaar HPF, Meinders AE, Schwarz F (1985): Metabolic responses during modified fasting and refeeding. Hum Nutr Clin Nutr 39C: 17.

Levy AB, Dixon KN, Malarkey WB (1988): Pituitary response to TRH in bulimia. Biol Psychiatry 23:476.

Morley JE, Shafer RB (1982): Thyroid function screening in new psychiatric admissions. Arch Intern Med 142:591.

Norris PD, O'Malley BP, Palmer RL (1985): The TRH test in bulimia and anorexia nervosa: a controlied study. $J$ Psychiatr Res 19:215.

Obarzanek E, Lesem MD, Goldstein DS, Jimerson DC (1991): Reduced resting metabolic rate in patients with bulimia nervosa. Arch Gen Psychiatry 48(5):456-462.

Petersen R, Kaye WH, Gwirtsman HE (1986): Comparison of calculated estimates and laboratory analysis of food offered to hospitaiized eating disorder patients. J Am Diet Assoc 86:490.

Pirke KM, Fichter MM, Pahl J (1985a): Noradrenaline, triiodothyronine, growth hormone, and prolactin during weight gain in anorexia nervosa. Int $J$ Eating Disorders 4:499.

Pirke KM, Pahl J, Schweiger U, Warnhoff M (1985b): Metabolic 
and endocrine indices of starvation in bulimia: a comparison with anorexia nervosa. Psychiatry Res 15:33.

Rattle SJ, Purnell DR, Williams P, Siddle K, Forrest GC (1984): New separation method for monoclonal immunoradiometric assays and its application to assays for thyrotropin and human choriogonadotropin. Clin Chem 30:1457.

Serog P, Apfelbaum M, Autissier N, Baigts F, Brigant L, Ktorza A (1982): Effects of slimming and composition of diets on $\mathrm{VO}_{2}$ and thyroiu hormunies in healthy subjects. $\mathrm{Am} \mathrm{J}$ Clin Nutr 35:24.

Spaulding SW, Chopra IJ, Sherwin RS, Lyall SS (1976): Effect of caloric restriction and dietary composition on serum $T_{3}$ and reverse $\mathrm{T}_{3}$ in man. $J$ Clin Endocrinol Metab 42:197.
Symons RG, Vining RF (1985): An evaluation of fluorescence polarization immunoassay of thyroxine and thyroxine uptake. Clin Chem 31:1342.

Vagenakis AG, Burger A, Portnay GI, et al (1975): Diversion of peripheral thyroxine metabolism from activating to inactivating pathways during complete fasting. J Clin Endocrinol Metab 41:191.

Weltzin TE, Fernstrom MH, Hansen D, McConaha C, Kaye WH (1991): Abnormal caloric requirements for weight maintenance in patients with anorexia and bulimia nervosa. Am J Psychiatry 148(12):1675-1682. 